Paper No. 6496

\title{
The main building for the 7 thousand million electron-volt proton synchrotron at Harwell $\dagger$
}

by

Stanley Albert Rossiter, B.Sc.Tech., M.I.C.E.

and

\section{John Stewart Brown}

\section{Discussion}

Mr A. E. Powell (Partner, Merz and McLellan, Consulting Engineers) said that his first impression on reading the Paper had been that it was an excellent example of the use of a steam-hammer to crack a nut. The nut which the physicists were attacking, however, was very much smaller than usual, and the hammer was a very large and complicated affair, the purely civil engineering side of which was dealt with admirably in the Paper. The complexity and advanced design of the electrical and mechanical portions of the machine should not, however, be overlooked. Since the Authors had necessarily had to treat the plant cursorily in order to deal with the very interesting design problems associated with the main building, he would like to bring the plant side into perspective in relation to the building work.

66. The 7,000 tons of main magnet housed in the building described in the Paper comprised sections which had been fabricated from special steel to a high degree of accuracy and, after careful determination of the magnetic characteristics of the various sectors, had been placed in the most suitable order and set in position with extreme accuracy. To assist in this work, very precise surveying techniques had been required, and Hilger and Watts had developed special apparatus which he hoped would be described at some other time by the Authors or some of their colleagues. The magnet had to keep its design position within very fine limits. It had therefore been necessary to ensure that the very large mass of concrete, on which it rested, not only should be stable in relation to the ground but that change of dimensions and shape on account of temperature variations should be minimized. To help achieve this an airconditioning plant had been provided which could remove from the magnet room the heat lost in the magnet sectors while on load or prevent cooling of the sectors when the synchrotron was not in operation. The air for this service was ducted through the foundation itself.

67. In the pre-commissioning period very careful studies had been made of the behaviour of the concrete under various conditions. In order to maintain thermal stability of the concrete, special heating cables were provided which were energized when the machine was not on load, to replace the heat loss occurring in the main cables carrying current to the magnet under working conditions.

68. The requirements of the civil engineering designers had in many places made life difficult for the plant designers by restricting access for the large number of service pipes, while economics dictated the necessity of limiting the height of areas bounded by very heavy walls, resulting in a special design of overhead crane to work in rather restricted headroom.

69. The Authors referred to the complications introduced in the civil engineering design by the requirements of the designers not only of the synchrotron itself but of the various services. Apart from the features so well described by the Authors he would

† Proc. Instn civ. Engrs, vol. 20 (October, 1961), pp. 259-274. 
emphasize the difficulty of providing access for the ventilating air input and extraction; access for large numbers of cables and pipes and the special design of certain of the shielding blocks to enable jacking trolleys to be run under them. These special blocks had been subject to the same unusually severe dimensional tolerances as the remainder of the blocks. It had sometimes been found that the solution of one difficulty helped greatly in solving others. For instance, the Authors had described how the decision had been reached to adopt a cellular structure for the magnet foundation and how it had been necessary to extend the shielding-bridge monolith to the east in the form of a cellular abutment. While it had been immediately appreciated that the cells under the magnet-room fioor would be useful for the services, he was sure that their value to the plant and service designers had been far greater than had been originally envisaged. The cells in the shielding-bridge abutment had proved invaluable for the accommodation of electrical switchgear and other plant, releasing valuable experimental space in the main areas to the physicists.

70. The requirement for heavy shielding of the magnet room had brought in its train many difficulties admirably solved by the civil engineers, as the Authors had shown. Perhaps if the shielding had not been so heavy, and therefore the magnet room had been less well insulated thermally, the difficulties of temperature control in the magnet room and its foundations would have been greater than in fact had been the case. The central column in the magnet room had been put to very good use by the mechanical engineers, who had treated it as a maypole about which to swing a 5-ton overhead crane, thus providing a variation on a theme seen elsewhere at Harwell and Dounreay where cranes spanned the diameter of a circular track.

71. There had been very close co-operation throughout, between those responsible for the main plant, and the design and construction engineers concerned with the building and services. Real problems had frequently arisen and been thrashed out from every point of view until the best solution had been reached. This had been nearly always a compromise which involved re-thinking and improvisation and sometimes frustration for one or more of the sections concerned. The successful completion of the bui'ding was in itself a great tribute to the splendid co-operation which had been achieved between the very many people concerned in one way and another.

72. It would be noted that provision was made for a power supply of about $20 \mathrm{MW}$, while cooling plant to dissipate about $20 \mathrm{MW}$ of waste heat was installed. This suggested that in terms of thermal efficiency Nimrod did not expect to shine; but it was possible to have faith in the explorations into the unknown to be made by the physicists with the use of the tool which had been provided, and that they would make worth while the skill and the effort so well described by the Authors.

Mr C. R. Lee (Principal Scientific Officer, Building Research Station) referred briefly to some observations made by the Building Research Station at two of the structures described by the Authors. The observations on the shielding bridge had been made at the invitation of Merz and McLellan and had been of particular interest because of the very large size of the beams. Strains had been measured by acoustic strain-gauges which had been fixed to the reinforcement before construction and which had shown excellent long-term stability. Deflexions had been measured by reference to tensioned wires stretched along the sides of the beams, the fittings for which could be seen in Fig. 17.

74. Since the soffit supports had been struck in February 1959, there had been excellent correlation between the B.R.S. strain and deflexion readings, taking into account of course, any change in temperature gradient through the depth of the beams. They had found that the neutral axis of the beams was progressively dropping, a fact of considerable interest because it indicated fairly substantial creep in the concrete. If, for example, a triangular distribution of stress in the concrete were assumed, the effective modulus of elasticity had already dropped from more than $4 \times 10^{6}$ down to about $0.8 \times 10^{6} \mathrm{lb} / \mathrm{sq}$. in. The deflexions of the beam were still increasing, but at a 
decreasing rate, and the additional deflexion since the soffit supports had been struck was now about 0.2 in., an amount probably not sufficient to endanger the clearance over the shielding blocks below the beam. It was interesting to note that their observations indicated that the beams had already become self-supporting to the extent of at least $90 \%$ even before the soffit supports had been removed. That had probably been due to compression of the timber puncheons.

75. As with most massive concrete structures, there had been a fairly considerable temperature rise due to heat of hydration and they had recorded maximum temperatures of about $125^{\circ} \mathrm{F}$. The cooling subsequent to this had not led to noticeable joint openings, probably due to the gradual settlement onto the soffit supports to which he had already referred.

76. Massive concrete structures dried only very slowly in normal circumstances and this had been confirmed for the shielding beams by observations on arrays of special moisture gauges which had been embedded in the concrete. These moisture gauges operated on the principle of electrical conductivity and must still be regarded as somewhat experimental. It seemed, however, to be fairly clear from the observations that drying at present was restricted to the concrete near the underside of the beam, where it was probably encouraged by a draught of air over the top of the shielding blocks.

77. The effects of temperature change, drying shrinkage and creep to which he had referred in relation to the shielding bridge also entered into the problem of the dimensional stability of the foundation monolith, concerning which the Building Research Station had been consulted by the Atomic Energy Authority. Some of the permitted dimensional tolerances had been quoted in the Paper; another which was of special interest in the B.R.S. study was the very small tolerance on radial tilt of the magnets, amounting to only $\pm 10 \mathrm{sec}$. of arc. Their view had been that accuracy to those limits was vulnerable not only to changes in the average conditions throughout the concrete but also to small differences between the top and bottom of the monolith, either in temperature or in the rates of drying encouraged by the rather different exposure conditions to which the top and bottom slabs of the monolith were subjected. In fact, it could be shown that a difference in shrinkage strain between the top and bottom slabs of only 16 millionths inch/inch, averaged over the whole monolith, would account for the tolerance on radial tilt which had been specified. In addition, there might be changes due to changes in loading or foundation reaction. They had felt, however, that creep effects would probably be of comparatively secondary importance.

78. To explore the various possibilities, vertical arrays of moisture gauges and thermocouples had been embedded, in March 1959, in sixteen holes drilled through the top and bottom slabs of the already-completed monolith. In December 1959, inserts had been embedded at eighteen positions in the floors and roofs of the catacomb rooms and ventilating duct for use with a 20-in. demountable strain-gauge. Observations had been made at two-monthly intervals. The problem of attaining dimensional stability in the foundation monolith had undoubtedly been complicated by the proposed use of the catacomb rooms for ancillary equipment, some of which generated heat, and by the use of the unlined annular duct in the monolith for the circulation of air. During the operation of the synchrotron this air would be used to cool the magnets, but during construction the circulation of air had been used to heat up the whole structure to its operating temperature of about $70^{\circ} \mathrm{F}$.

79. High velocities had been employed and, on occasions, quite high temperatures as well, and it was thought that these contributed to the appreciable drying which in fact appeared to be occurring. There had also been some temperature fluctuations. To meet the urgent needs of the engineers erecting the magnets they had made quantitative estimates, necessarily somewhat tentative, of the rates of drying and consequent shrinkage, so that suitable allowances could be made in the setting out of the magnet positions. It would seem that dimensional stability of the concrete monolith of the very high order required by the physicist would not be easy to guarantee over long periods and some later readjustment of the magnets might be necessary. Further comment by 
the Authors, or perhaps by the Survey Group, on actual survey or alignment experience would be of considerable interest.

Mr J. G. Knibb (Civil Engineer, United Kingdom Atomic Energy Authority) said that accuracy had been a frequently recurring theme. Each of the 200 shielding blocks of $12 \frac{1}{2}$ tons or 25 tons had been specified to be accurate to $\pm \frac{1}{16}$ in. and the 28 mutually parallel rails for the transporting of these blocks were to have their gauge accurate to $\pm \frac{1}{32}$ in. Whilst the skill of craftsmen is a critical factor in the standard of any articles they produce, yet the measure of consistency of the shield blocks in particular is a tribute to the carpenters who made them and the technician who measured them.

81. Mr Knibb said that the centre column contained a centre point installed at no small nervous expense by site staff but now ignored by the client. During construction simple mild steel datum plates had been installed in the magnet room floor using conventional survey equipment. These had been resurveyed later, by large scale metrology techniques, measuring each dimension six times to 0.001 in. and each angle to $1 \mathrm{sec} .24$ times. These values, with extra tie lines, were fed into an electronic computor which calculated the inaccuracy in each point. Special datums were then reset relative to the construction datums to an accuracy of thousandths of an inch. These were then resurveyed as before and it appeared that the average inaccuracy had been reduced by about half.

82. Mr Knibb said that Nimrod highlighted a potentially important philosophical question. After explaining that Nimrod was a gigantic Pandora's box full of peculiar particles to be studied, he pointed out that an eminent scientist had said that Nimrod's results might turn out to be the absolute in fundamental research and be of no practical application. Mr Knibb asked the members to consider the nature of the driving force behind this project and so to ponder the objectives to which all human endeavour was being directed, or should be directed.

Mr A. Chivers (Managing Director, W. E. Chivers \& Sons Ltd) said that the technical details had been given by previous speakers, but he wished to add a little information about the start of the work and the materials used. Among the major items of materials used were $115,000 \mathrm{cu}$. yd. of concrete, with a guaranteed crushing strength of 2,000 to $8,000 \mathrm{lb} / \mathrm{sq}$. in., 5,200 tons of rod reinforcement ranging from 2 in. to $\frac{1}{4}$ in. dia., and $2,000,000$ bricks. The preliminary work before the main contract had involved the removal of $160,000 \mathrm{cu}$. yd of chalk in 14 weeks. They had begun with bulldozers and scrapers and gradually worked down until it became necessary to use excavators towards the bottom, and the whole of that $160,000 \mathrm{cu}$. yd had been cut out in 14 weeks, so that whoever was to be the main contractor was able to get straight to work.

84. They had used three 120 -ft jib Scotch derricks and $60 \mathrm{ft}$ jib mobile cranes to place the material. The concrete plant, which they had designed themselves, was made by a Bath firm, and was not of the ordinary straight type but of V-shape with two 1-cu. yd mixers so that the transporters could collect $2 \mathrm{cu}$. yd from each wet hopper at the same time. They had placed at one period as much as $560 \mathrm{cu}$. $\mathrm{yd} /$ day in the monolith, their average being $200-300$ tons/day.

85. After experimenting with several methods of jacking they had come to the conclusion that the most positive method was to use sand boxes, and these had been designed in their workshops at Devizes. The designer, who had also been their chief estimator at the time, worked on the principle of the old-fashioned egg-timer, with the sand going from one section to the other. To be able to release the boxes at the top there were two tubes, one inside the other, so that they could take sand out and transfer the weight to the permanent bearings. The sand boxes were 21 in. $\times 5$ in. $\times 3$ in. deep.

86. To support the concrete roof they had used timbers of $50-\mathrm{ft}$ span. They had considered whether to use steel girders or timber, but he had in mind the preference of miners for timber rather than steel for supports, because they could hear the timber cracking but could not do so with steel when there was overload. The trusses weighed 
approximately 6 tons and the trestles were approximately the same weight. To move them from section to section, as they weighed 6 tons, heavy skates were used, and in that way it had been found possible to move them in a circle very much more quickly than by other means. The skates used were small but very efficient.

87. The shielding blocks had already been described and the two critical dimensions of $\pm \frac{1}{16}$ in. Chivers had made their own shutters, $6 \mathrm{ft} \times 3 \mathrm{ft}$ entirely of timber, because they specialized in the use of timber. The timber shuttering was made of a 3 in. $\times 2$ in. frame with a hardboard face on the front, properly treated, with a very smooth finish, and that had been very successful.

BOREHOLE I

G.L. 247.9' O.D.

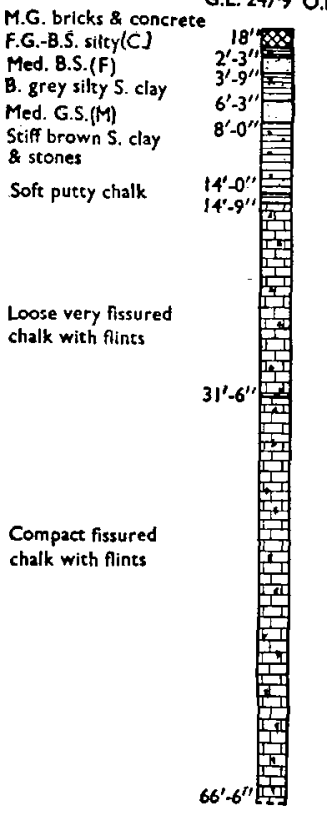

Made ground

Soft B.-G.C. silty S

Loose to med. B.G

silty $S$.
F.8.-blue-grey silty C. $3^{\prime}-0^{\prime \prime}$
with seam of yellow B $5.6^{\prime}-0^{\prime \prime}$

with seam of yellow B S. $\frac{6^{\prime}-0^{\prime \prime}}{7^{\prime}-9^{\prime \prime}}$

silty C. with shell

fagments

Small pleces of chalk

G. buff silty matrix

Loose very fissured

chalk with flints

Putty chalk

Compact fissured chalk

with layers of putty

chalk \& flints

Compace fissured chalk with flints

KEY

M.G. = made ground

med. = medium density

S. = sand (or sandy)

G. $=$ green

C. $=$ clay

L. $=$ loose

B. = brown

$F$. = firm

(FMC) = Fine, medium, and coarse grained

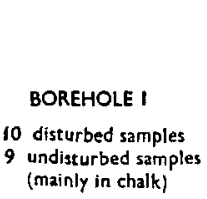

BOREHOLE 2

G.L. 245.6' O.D.

II'-0"

$2 \cdot 6 "{ }^{\prime \prime}$

Loose M.G; gravel.

BOREHOLE 4

bricks, earth

G.L. 256.5'O.D.

Soft B.S.C.

\& stones. $\frac{5}{7^{\prime}-3^{\prime}}$

Gravel (C)

in soft B.C.

Compact graveli $C$

traces of clay and

large fint stones

Compact sandy gravel (C)

$24^{\prime}-9^{\prime \prime}$

Stiff grey silty $27^{\prime} \cdot 0^{\prime \prime}$
C. \& stones- $30^{\prime} \cdot 0^{\prime \prime}$
Flrm G. sandy
clay \& stones

L. very fissured chalk with flints

Compact fissured chalk with

soft layers

\& flintstones

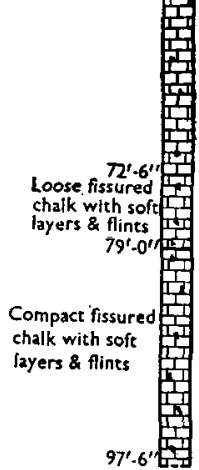

BOREHOLE 2

12 disturbed samples

3 undisturbed samples (mainly in chalk)

\section{BOREHOLE 4}

13 disturbed samples

14 undisturbed samples (mainly in chalk)

Fig. 21.-Subsoll conditions at Site A 
Mr T. R. M. Wakeling (Director, Foundation Engineering Ltd) discussed the soil mechanics aspect of the design of foundations on soft rocks. These strata, which from the point of view of sampling or testing were neither rock nor soil, presented a problem which was not easy to solve. The Authors had described in considerable detail the method which they had used to predict the bearing capacity and settlement of the magnet foundation and he would like to present an alternative method which he had used for a comparable site on soft rock at Newbury in Berkshire. The investigation had been at the sites for two bridges, where settlement was important. The consulting engineers were Messrs Howard Humphreys \& Sons.

89. Fig. 21 showed the subsoil conditions at the first site. Work started at Borehole 2 using shell and auger equipment, and extremely soft chalk had been encountered.

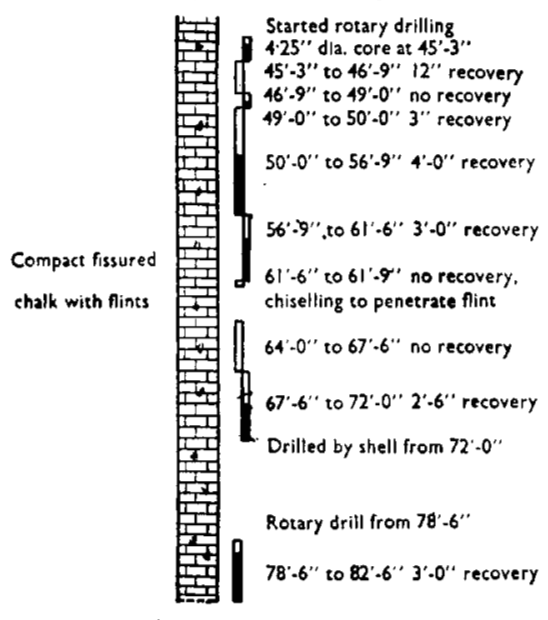

DETAILS OF ROTARY CORING IN BOREHOLE 2

Fig. 21a-DetaIl FROM Fig. 21

Standard penetration tests were carried out and 4-in. open drive samples were successfully recovered in all but the exceptionally soft upper part of the chalk. It was originally planned to take rotary cores of the chalk but owing to its softness, this was not attempted until a depth of $\mathbf{4 5} \mathrm{ft}$ had been reached. A large rotary core barrel cutting 4-in.-dia. cores was used in an attempt to get the best possible cores, but even with this, the core quality was extremely poor because the chalk was soft and broken, with numerous flints. Proposals to determine the properties of the chalk by testing the cores were abandoned, and it was decided to take 4-in. dia. open drive samples alternating with standard penetration tests in all further boreholes. The intention was that the 4-in. samples would be tested in the laboratory and these test results would be correlated with the standard penetration test values.

90. Fig. 22 showed the subsoil conditions of the second site. Here the chalk was overlain by river gravels but otherwise its consistency was very much the same as at the first site and similar low values of standard penetration test were obtained.

91. Fig. 23 gave the variation of standard penetration test values with depth for the two sites. This showed that there was a general hardening with depth and that the upper very soft chalk was about $20 \mathrm{ft}$ thick.

92. In the laboratory, tests were carried out in a large triaxial cell on chalk samples 8 in. long and approximately $4 t$ in. dia., as extruded from the sample tube. This size was considered to be the smallest that could yield useful test results for this type of material. The apparatus permitted the measurement of the shear strength in terms of 
both total and effective stresses and also the determination of the consolidation characteristics.

93. The majority of samples were consolidated in the triaxial apparatus under cell pressures within the range of normal overburden pressures, and pore-water pressures were measured during the compression test. The shear strength characteristics were plotted in terms of both effective and consolidation pressures, and it was found that the corresponding standard penetration test values had no significant effect on these results. The results were given in Fig. 24. The consolidation results indicated a low compressibility together with a high rate of consolidation and again there was no signifcant variation with standard penetration test value.

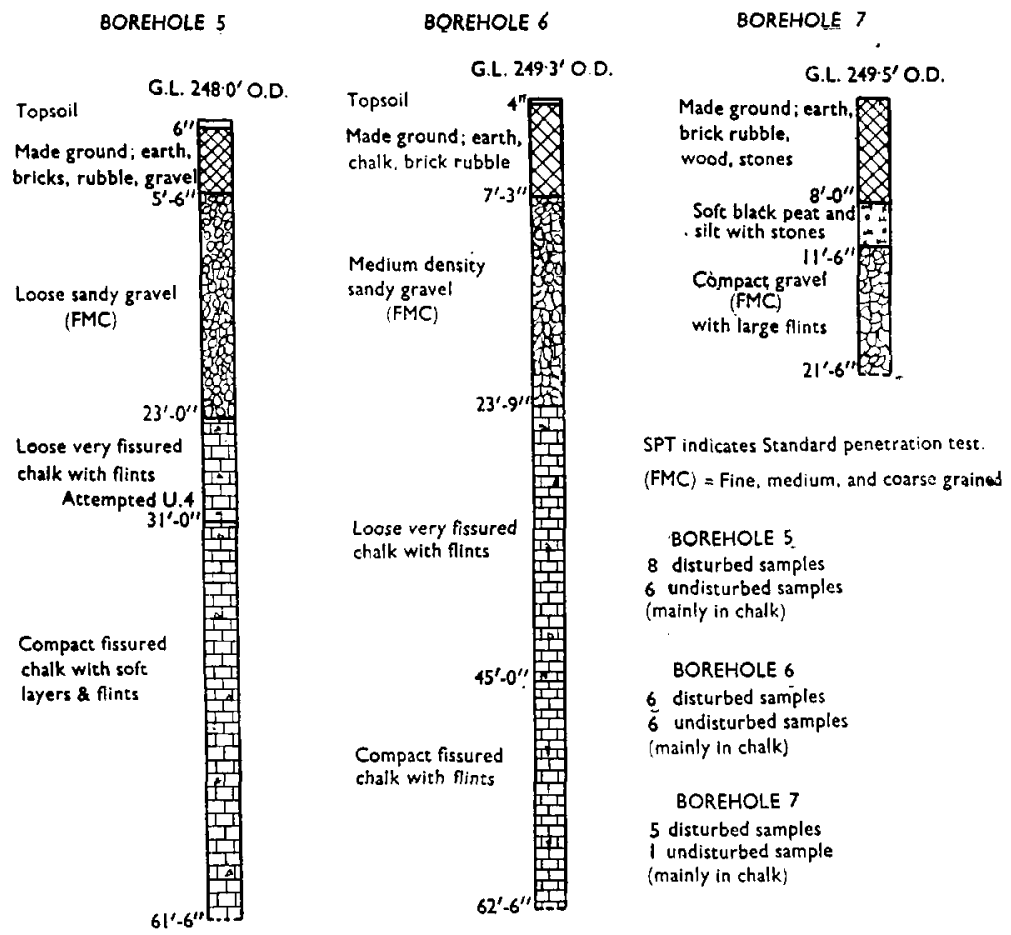

Fig. 22.-SuBsoll CONDITIONS AT Site B

94. The modulus of elasticity was determined from the triaxial compression tests and the results varied considerably with the consistency of the chalk. There was a reasonable working correlation with standard penetration test values which was shown on Fig. 25. In the softer chalk the scatter was considerable, but this was thought to be due to the very poor sample recovery in this range. It was very probable that below a standard penetration test value of 10 blows per $\mathrm{ft}$, soft fissured chalk lacked sufficient cohesion to be recovered in a sampler, and therefore the scatter represented the random harder lumps which were recovered.

95. The test results indicated that the general properties of the soft fissured chalk were comparable to a granular soil in which the frictional strength was high, the volume compressibility was low, and the modulus of elasticity increased with density. This 

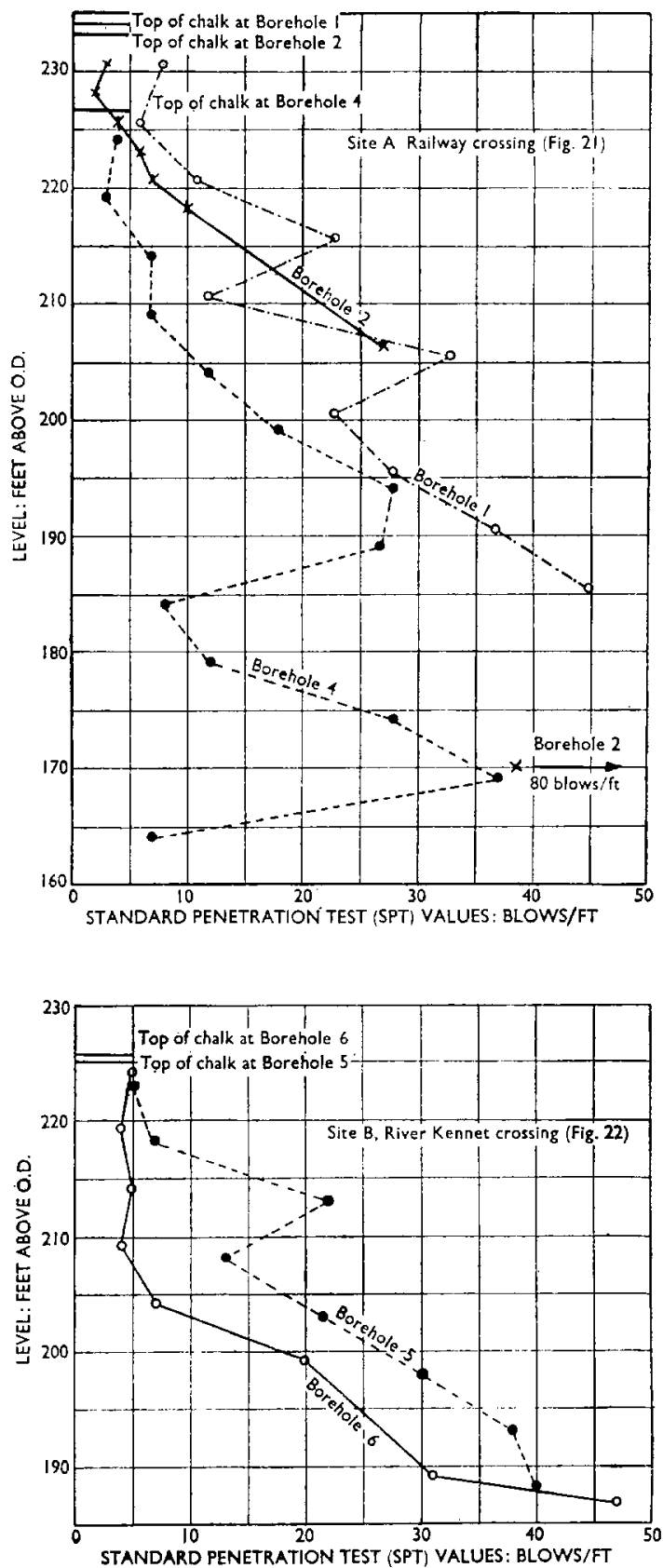

FIG. 23.-VARIATION OF STANDARD PENETRATION TEST WITH DEPTH 

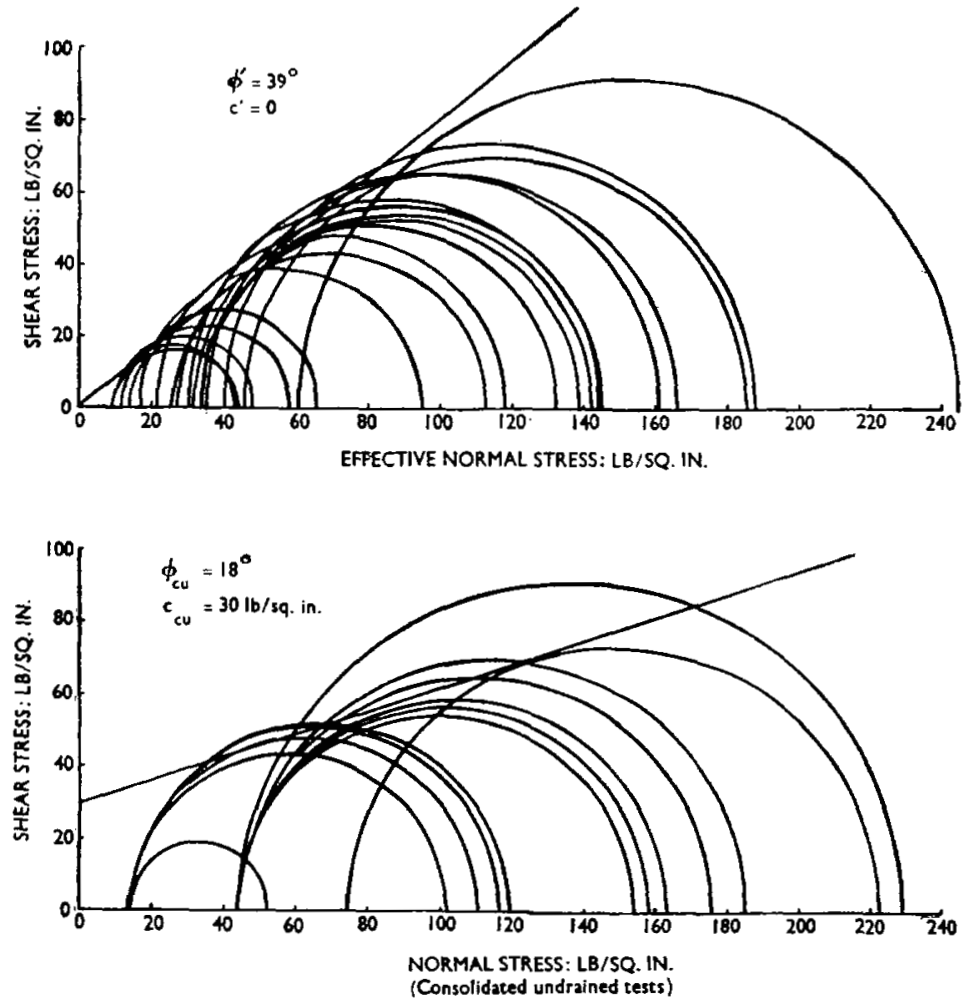

Fig. 24.-Results of triaXial tests (4.2 IN. DIA. SAMPLE)

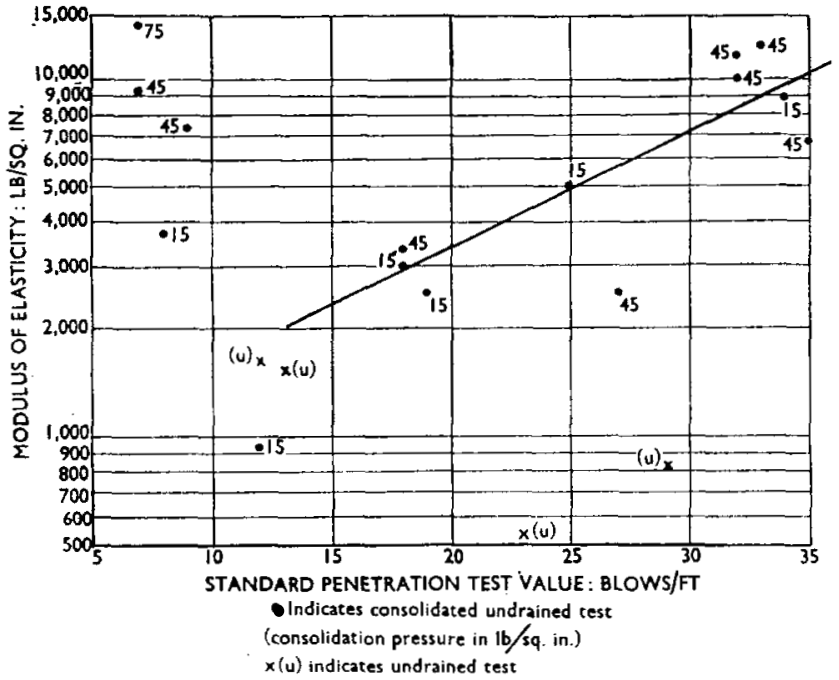

Fig. 25.-VARIATION OF MODULUS OF ELASTICITY WITH STANDARD PENETRATION TEST 
meant that whereas the ultimate bearing capacity and consolidation settlement were favourable, the immediate settlement was very critical. The general properties of the chalk were summarized in Table 2.

\section{TABLE 2.-SUMMARY OF TEST RESULTS FOR SOFT CHALK}

(i) Shear strength

Effective stress parameters: $\phi^{\prime}=39^{\circ} \quad C^{\prime}=0$

Consolidated undrained tests (total stresses): $\phi_{\mathrm{cu}}=18^{\circ} \quad C_{\mathrm{cu}}=30 \mathrm{lb} / \mathrm{sq}$. in.

(ii) Modulus of elasticity

$\begin{array}{cc}\text { Standard penetration } & \text { Modulus of elasticity: } \\ \text { test: blows per foot } & 1 \mathrm{~b} / \mathrm{sq} . \text { in. } \\ 15 & 2,000 \\ 20 & 3,000 \\ 25 & 5,000 \\ 30 & 7,000 \\ 35 & 10,000\end{array}$

(iii) Consolidation

Coefficient of volume compressibility (Mv) 0.002 sq. $\mathrm{ft}$ per ton

Coefficient of consolidation (c) 0.36 sq. $\mathrm{ft}$ per ton.

96. Mr Wakeling was very interested in the settlement figures which Mr Rossiter had given in introducing the Paper. Not having had those available, he had attempted to compare his data with the results of the plate bearing tests. Considering the test with the larger plate, which was probably more representative, the modulus of elasticity was equivalent to a standard penetration test value at Newbury of between 25 and 30 blows per $\mathrm{ft}$. From normal experience of chalk this appeared to be a reasonable agreement and it might be considered therefore that the transference of those readings to another comparable site would give reasonable results.

97. At the sites where he had carried out the investigations described, the bridges had not yet been built, so that there was no adequate check on the accuracy of the settlement predictions. He was therefore extremely interested in the data for the Harwell site and hoped that the Authors would be able to continue their settlement observations.

Mr T. C. Waters (Chief Structural Engineer, United Kingdom Atomic Energy Authority) said that the subject of tolerances had been dealt with fairly fully already and he would accordingly restrict his comments to those concerned with settlement and tilting. Having had experience of physicists and their requirements for some 15 years he knew something of the civil engineer's problems in attempting to comply with their requirements. Most civil engineers had experience of the dimensional requirements of the mechanical engineer. The relationship between the physicist and the mechanical engineer was just as remote, and to bridge the gap between what the physicist required and what the civil engineer could give demanded a good deal of hard bargaining on the part of the civil engineer. The Authors were to be congratulated on bringing the physicists down to earth.

99. In $\$ 50$ the Authors discussed the practicability and the financial aspects of different methods of constructing the roof of the magnet room and gave their reasons for doing the work in situ. Associated with this was the general programme of shielding block casting, and the casting of the shielding blocks appeared later to have been set back in the programme. His feeling was that the use of precast prestressed beams for supporting the roof would have been worthy of a good deal of consideration, and perhaps reconsideration in view of the rearrangement of the programme. It would be interesting to know whether or not the Authors had any views on that at the present stage. His point was that it would have enabled work to be carried out below the roof 
during a fairly long period of construction and it might well have led to a measure of balanced construction on the site.

100. With regard to the 4,000 tons of removable blocks, he wondered whether or not consideration had been given to the use of high-density aggregates for these, rather than ordinary aggregates. With the use of aggregates, as barytes, ilmenite, or magnetite, a density of $220 \mathrm{lb} / \mathrm{cu}$. ft could have been achieved, with a resultant reduction in storage space of something like one-third as compared with those for ordinary aggregates. A financial problem would have been involved, because the initial costs would have been considerably higher than with the use of ordinary aggregates; but, bearing in mind both storage and handling, they might well have paid for themselves in the long run.

101. For the shielding beam the Freyssinet hinges at the east abutment were set at approximately $45^{\circ}$ to the axis of the beam. He was doubtful about their being able to function satisfactorily; he would have liked to set them in line with the axis to give them an opportunity of moving in the manner in which they were designed to move.

102. In $\S 30$ the shielding beam was referred to as "dog-legged", and he asked himself "Why have a dog-legged beam?" So far as he could see, the reason for it being dog-legged was to carry in the most economical manner the roof of the magnet room and the circular crane. He wondered whether or not he might offer an alternative solution, in the hope that the Authors would comment on it. His idea would be to throw the shielding beam straight across from the west abutment to the east abutment and at right-angles to them. He would also throw a relatively light beam (but it would have to be a deep one) from the shielding beam at about $45^{\circ}$ on to the east abutment to carry the crane and that part of the roof. On the debit side it would mean carrying rather more roof, rather more dead load, but on the credit side it would eliminate the rather expensive and delicately-poised central column. It would span the distance in the shortest possible way, and the Freyssinet hinges could be set in a manner which would give them ample opportunity to work in the manner for which they were designed. He believed that the foundations for such a beam could be dealt with as a monolith in a similar manner to that of the Authors without exceeding the unit loads which were permitted for the job.

103. In looking at the catacombs in the monolith construction he would like to refer to the fillets and mitres that were provided there. They seemed to be rather lavish. They must have been expensive and must also have set the carpenter a good many problems in shuttering and the concretor a good many problems in pouring and compacting. Mr Water's inclination would have been to omit them if at all possible, but the Authors might be able to give good reasons for their use, which might be associated with the pulsing of the magnet.

104. He was glad to note from $\S 43$ that instrumentation had been provided to measure temperatures and strains in the superstructure during and after concreting. All too little was known about the properties of concrete and the Authors were to be congratulated on their foresight in seeking to add a little more information to the very small store which existed at present.

Mr G. L. Hargreaves (Deputy Director of Navy Works, Admiralty) said that from what was said in $\$ 26$ the effects of the pulse from the magnet seemed to be in the nature of an impact load. Perhaps the Authors would expand a little on that in due course.

Mr E. G. Higgins (Design Engineer, National Institute for Research in Nuclear Science, Harwell), as one who had been associated with the survey and alignment problems of the machine, referred to the tolerances which had been laid down and which were given in the Paper. The Authors had made it clear that these were for the operational period of the machine. He proposed to give a few figures of the actual experience at a time when far greater movements might perhaps be expected than 
when the machine had settled down. Mr Rossiter in presenting the Paper had mentioned a settlement of 1 in., but that did not agree with the figures Mr Higgins had obtained. From the time that the top of the monolith had been cast until November 1961, the settlement had been about 0.4 in., and for the shielding beam about $\mathbf{0 . 3}$ in. To that must be added the somewhat nebulous amount of settlement which had taken place from the time that the protective concrete had been laid until the time when the top of the monolith had been cast, probably about $\frac{1}{4}$ in. The total settlement from the time that the protective concrete had been laid was difficult to assess but was probably about $0.65 \mathrm{in}$.

107. The behaviour of the monolith itself had been recorded by a fairly orthodox survey method using a ring of 8 internal datums round the central column, of about $32 \mathrm{ft}$ dia., and a ring of outer datums, of which there were 16, at a radius of $65 \mathrm{ft}$. From the time of the first precise height survey in September 1959, to which Mr Knibb had referred, bending and distortion generally had taken place. They had assumed when the first survey was done that the monolith was flat. About 4,000 tons of shielding blocks had been put in position in August 1959, and surveys in September and December of that year showed a saucer effect. The centre of the monolith was of the order of 0.020 in. below the outer point, and there was a tilt on the monolith of about 0.035 in. toward the point of loading.

108. Between that date and November 1961, the height surveys had gone on regularly and other distortions had taken place. The tilt to which he referred had wandered in an anticlockwise direction and the position today was that the monolith was now an inverted saucer, the outer datums being $0.010 \mathrm{in}$. lower than those in the centre. There was a bend roughly on the magnet-room axis normal to the experimental area and towards the shielding beam, of about 0.035 in. It had been shown, he did not know how reliably, that the earth mounding, which was the main contributor to the troubles experienced, caused a distortion of about 0.001 in. per 100 tons, but not necessarily according to a regular pattern. The magnet loading might be responsible for the reversal of the shape of the saucer.

109. It was worth bearing in mind that from the beginning of the job every effort had been made to complete as quickly as possible the roof and side loadings, the earth mounding as well as the concrete, so as to give the monolith an opportunity to settle down and take up its permanent position before the magnets were aligned. For various reasons this had not been possible, and they had had to live ever since with the disturbance which this caused. It had caused considerable trouble and the appropriate adjustment now had to be made on the alignment of the pole pieces, which required some sacrifice on the part of the physicists.

\section{The following contribution was received in writing:}

Mr E. L. Barron (Project Leader, Brandt \& O'Dell) wrote that the limits of the magnet-foundation movement originally specified by the scientists were typical of the very close tolerances that engineers were increasingly being asked to obtain on large structures. What tolerances were stipulated after the detail modifications to the machine? Did the modifications include provision for adjustment to compensate for settlement in excess of that anticipated?

111. It would appear that the rigidity of the structure and the uniformity of the loading were considered adequate provision for the distortion and tilt tolerances orginally specified, but the estimated settlement of the order of $1 \mathrm{in}$. initially and 2 in. over a very long period was very much larger than the $\frac{1}{4}$ in. originally specified. Could the Authors elaborate upon the arguments used to establish the engineering judgment of settlement and associated tilt? Did the initial settlement prove to be of the order of 1 in., and what was the corresponding tilt? 
The Authors, in reply, said that some of the contributions did not require a reply, being in fact additions to the Paper. Mr Powell had commented on the restrictions imposed by the mechanical and electrical work on the civil engineering work but he certainly appreciated that this was mutual, and neither would be there had not the physicists wished to have their peculiar machine.

113. Mr Powell emphasized the close and friendly liaison between the principal parties concerned-physicists, plant engineers, surveyors, civil engineers, architects and contractors. Not much had been said in the Paper about the part played by the contractors, because it was concerned with the design of the building rather than its construction and had had to be limited in that way to keep it to a reasonable length.

114. Mr Lee commented on the possibility of endangering the clearance of the shielding blocks. The risks of that were very low in relation to the magnitude of the deflexions which took place in the beam; and, as mentioned in the Paper, the principal safeguard was that the bridge and the blocks were both on the same foundation: if the bridge went down, then the support for the blocks went down too. The clearance for the blocks under the bridge was several inches, the top space being filled as required by steel bars.

115. Mr Lee remarked on the general interest of the work done by the D.S.I.R. Building Research Station and it would certainly be of very great help in a number of civil engineering problems. It had been amazing, when the Authors came to make their design studies, to find that the only information available on the drying of concrete comprised the results of tests on very small laboratory samples. Mr Lee and $\mathrm{Mr}$ Higgins had mentioned some of the extraneous causes affecting their readings and deductions up to date. Those effects were now being eliminated and the results still to be recorded by the B.R.S. and Mr Higgins's department should add considerably to the knowledge available. It was certainly most desirable that Mr Lee's and Mr Higgins's departments should be able to publish full reports on their very long-term measurements of the structures.

116. Mr Lee referred to the effects in the catacombs of heating from the additional plant which was being accommodated there. In order to limit these effects-both temporarily until the main ventilating and heating plants were available, and permanently -local artificial heating had been provided. Mr Higgins had replied to Mr Lee's question on alignment.

117. The Authors were particularly sorry that the centre point in the centre column had caused Mr Knibb so much difficulty. Mr Rossiter personally had been responsible for seeking to preserve access to the true centre of the magnet and the building. The physicists had tended to deride this from the outset and so far little use appeared to have been made of it.

118. To civil engineers it had been interesting to hear the difference in degree of accuracy of the surveys by the civil engineers and those of the survey team with their precise instruments and computations. The results gave one considerable confidence in the use of the civil engineer's conventional tools for setting out.

119. Mr Knibb had also commented on the accuracy of construction of the precast blocks and Mr Chivers also had dealt with this. It had been very satisfying to find how accurately the contractors had been able to make the concrete blocks using timber shutters. At the outset the attitude of the engineers had been that there must be a steel or cast iron mould for the precast blocks because it would not be possible to comply with the specified tolerances if timber shutters were used. Some consideration had been given to the use of cast iron, but due to the number of moulds required-not one but half a dozen-it would have been extremely costly. Prototype blocks cast in timber were so good that thereafter there had been little hesitancy in agreeing to the use of timber moulds.

120. Mr Knibb had been concerned about the degree of accuracy required in the setting of the rails for the blocks. The need for this very fine degree of tolerance was indicated by the explanation below. It must be practicable to move each stack of 
blocks on its trolleys without fouling its neighbours yet the clearance between blocks must be minimized. Each stack was cast as a stack, one block on top of another, five blocks high. Moulds were carefully plumbed during casting. Each block and each stack was separately referenced so that every block and every stack could always be replaced in the same position and orientation. The stacks were matched to compensate their neighbours' irregularities as far as possible. Yet there remained possibility for misalignment and cumulative inroads on tolerance due to

(a) the accuracies with which stacks could be re-formed.

(b) the accuracy with which the jacking trolleys could pick them up, transport them and set them down again.

(c) bearing clearances in the trolley wheels and

(d) clearances between rails and wheel flanges.

121. When the available clearance was shared between the rails and all these factors, all that could be afforded for rail straightness was $\pm \frac{1}{32}$ in.

122. Each member must provide his own answer to Mr Knibb's remarks on the philosophy of the nuclear scientists and of the builders serving them.

123. The Authors wished to take this opportunity to thank Mr Chivers for his firm's contribution to the success of the project. It might be that a Paper devoted to its construction would do the contractor more justice than the present Authors had been able to do in this Paper. The job had been a big and unusual one for the contractor and he had grappled with it extremely well. The complexities of the job had not been new to him; he had had years of experience of the requirements of the Atomic Energy Authority so that the close tolerances involved had been almost everyday stuff to Mr Chivers and his experienced team. His remarks, on the use of timber, well demonstrated that the man who was used to a material could use it with very good effect where another man would be happier with a different material.

124. Mr Wakeling's approach to a ground investigation problem in somewhat similar ground was very interesting. It would appear that the loads with which he was concerned would be of a somewhat lower order and that tolerances might be somewhat less stringent. Mr Wakeling had not indicated what his estimates of short- and longterm settlements were nor the load sizes or ground-bearing pressures envisaged.

125. Mr Wakeling had been surprised by the material found in his trial borings, just as the Authors had been at Harwell. There they had started work by receiving a report about another project extolling the suitability of the chalk downs of Berkshire for founding machines such as this, but when they took their trial pits and borings they had not been so happy about it.

126. Mr Waters asked whether it would not have been possible to use the prestressed precast concrete roof beams referred to in the Paper when it had been decided to modify the programme. There were one or two reasons why this would not have been practicable. At the time when the programme of casting the blocks was modified, the construction of the building had already started and the cranage available on the site was of too small capacity to deal with precast members of the size required; and it would not have been possible at that stage to organize the rapid construction of the large number of heavy and bulky precast units which would have been required. The use of heavy aggregates for the precast blocks had not been seriously considered by the Authors. Such a study had no doubt been undertaken by the Authority's project engineers at a fairly early stage, but by the time Mr Rossiter's firm came into the picture the main parameters had been settled and the decision to use blocks cast with normal aggregates had been taken. He did not know to what extent that had been influenced by the ancillary purposes for which it had been proposed to use the blocks. It was the intention to use these blocks to build what the physicists called "igloos"--shelters either over the magnet itself or in the experimental area for the local shielding of experimental equipment. Blocks of the size used were tall enough to stand on end and long enough to bridge over the magnet, but more dense blocks would not have done this so readily. 
Mr Rossiter had not quite understood Mr Waters' remarks about the handling problem. Presumably the more dense blocks would be at least as heavy, block for block, as blocks of normal aggregate, and might have been even heavier, so that if anything the handling problem might have been more severe if denser blocks had been used. The main advantage of heavy shielding undoubtedly was compactness. With such severe shielding requirements-many times that in the biological shield of a power reactor-cost was of considerable importance and the cheapest practicable material was used. Heavier blocks would have intensified the already very heavy concentrations of floor loading.

127. With regard to the Freyssinet hinges, a simple model experiment, as indicated in the Paper, had been made which showed that the predominant direction of movement of the hinges was parallel with the supports. The width of the bridge in relation to its span was large: it had not been a question of dealing with a long, slender member, where the deflexion might have been more nearly along the axis of the beam rather than parallel with the supports.

128. Mr Waters asked why a dog-leg beam had been used. The Authors had not wanted to have a dog-leg beam. The question had been raised in the design stages, and it had been insisted that the shielding should be as close to the magnet as possible. The desire had been to bring experimental equipment as close to the magnet as possible: it had been expected that experiments would be mounted in the triangular area lying immediately south of the east span of the bridge. One of the difficulties which had now been found was that the absence of heavy lifting facilities in the triangular area was limiting the use which could be made of it. The 30-ton overhead crane in the experimental area could not command the triangle.

129. It was true that with the square-span bridge suggested by $\mathrm{Mr}$ Waters the central column could have been omitted, but had that been done the cost of the bridge superstructure would have been greater. It would probably have been necessary to have a beam upwards of twice the depth of that in fact used to cope with shear, and the reinforcement would have been very much heavier. The cost of the foundation monolith would have been increased, since the foundation would in effect have been loaded with a two-point load rather than the three-point load in the present design.

130. Mr Waters had asked if the fillets between the walls and slabs in the catacombs could have been avoided. As these were dictated by shear requirements they could only go at the expense of much greater weight of concrete and loss of service space in the basement.

131. Mr Hargreaves asked for more information about the pulse effects mentioned in the early part of the Paper. The Authors could not do better than refer him to $\mathrm{Dr}$ Pickavance's and Mr Bowles' articles noted in the bibliography at the end of the Paper. Calculations regarding the resonance effects indicated that the low period of vibration of the foundation was satisfactory and that the stresses due to this cause were a very small proportion of the total stress.

132. Mr Rossiter apologized to Mr Higgins for inaccuracies in the statements about settlement and thanked him for the correction. He had been relying on his memory in giving them and was sure $\mathrm{Mr}$ Higgins' figures would be right.

133. Mr Barron had asked about the relaxations accepted by the physicists. These were simply the acceptance of the estimated settlements mentioned in the Paper. They entailed design of ancillary equipment to permit adjustment in level to match differential settlements between the magnet and ancillary foundations.

134. Mr Higgins had given the reply to Mr Barron's last question. 